九州大学学術情報リポジトリ

Kyushu University Institutional Repository

Introducing Viewpoints of Mechanics into Basic Growth Analysis (3) : Applying Growth Force and Leaf-Light Complex to Production and Digestion, Analyses of Forages

Shimojo, Masataka

Faculty of Agriculture, Kyushu University

Ikeda, Kentaro

Faculty of Agriculture, Kyushu University

Asano, Yoki

Employed Research Scientist, Miyazaki University

Ishiwaka, Reiko

Faculty of Agriculture, Kyushu University

他

https://doi.org/10.5109/9283

出版情報: 九州大学大学院農学研究院紀要. 52 (1)，pp.69-72，2007-02-28. Faculty of Agriculture， Kyushu University

バージョン :

権利関係 : 


\title{
Introducing Viewpoints of Mechanics into Basic Growth Analysis - (III) Applying Growth Force and Leaf-Light Complex to Production and Digestion Analyses of Forages -
}

\section{Masataka SHIMOJO*, Kentarou IKEDA ${ }^{1}$, Yoki ASANO ${ }^{2}$, Reiko ISHIWAKA ${ }^{3}$, Hiroyuki SATO ${ }^{4}$, Yutaka NAKANO ${ }^{5}$, Manabu TOBISA ${ }^{6}$, Noriko OHBA ${ }^{7}$, Minako EGUCHI ${ }^{8}$ and Yasuhisa MASUDA}

\author{
Laboratory of Animal Feed Science, Division of Animal Science, Department of Animal and \\ Marine Bioresource Sciences, Faculty of Agriculture, \\ Kyushu University, Fukuoka 812-8581, Japan \\ (Received November 10, 2006 and accepted December 1, 2006)
}

\begin{abstract}
The present study was designed to give new equations by applying growth force and leaf-light complex to production and digestion analyses of forages. The results obtained were as follows. The traditional equation for forage AGR (absolute growth rate) given by the product of NAR (net assimilation rate) and LAI (leaf area index) was modified as follows: (1) AGR was replaced by growth force that was given by the product of weight and growth acceleration, (2) LAI was replaced by MLA (mean leaf area weighted with relative light intensity) suggesting a kind of leaf-light complex. Inserting growth force and MLA into the traditional description of AGR led to a new equation, where growth process of forages was analyzed more deeply. The application of growth force to indigestible materials in forages gave a new equation that analyzed the indigestibility increase with forage growth more deeply compared with the former equation. It was suggested that growth force and leaf-light complex were useful tools in the production and digestion analyses of forages.
\end{abstract}

\section{INTRODUCTION}

In a paper (Shimojo et al., 2006) we suggested three aspects of growth mechanics that were compared with three laws of motion (Kawabe, 2006), where relationships among weight, absolute growth rate and growth acceleration gave a concept of growth force that might resemble Newton's equation of motion in appearance. However, it does not seem that growth force has been applied to basic growth analysis. The dry matter productivity by plant leaves (Watson, 1952; Radford, 1967; Hunt, 1990) based on light environment in plant canopy (Monsi und Saeki, 1953; Monteith, 1965) is a factor of importance to forage production. Shimojo et al. (1995a, 1998e, 2004) gave an equation suggesting a kind of leaf-light complex in plant canopy, an index that might be related to light receiving performance of canopy leaves.

The present study was designed to apply growth force and leaf-light complex to production and digestion

1 Former Research Fellow, Faculty of Agriculture, Kyushu University

2 Employed Research Scientist, Miyazaki University, Miyazaki 889-2192, Japan

3 Research Fellow, Faculty of Agriculture, Kyushu University

${ }^{4}$ Laboratory of Animal Feed Science, Division of Animal Science, Department of Animal and Marine Bioresource Sciences, Graduate School of Bioresource and Bioenvironmental Sciences, Kyushu University

5 University Farm, Faculty of Agriculture, Kyushu University

${ }^{6}$ Faculty of Agriculture, Miyazaki University, Miyazaki 889-2192, Japan

${ }^{7}$ Former Research Student, School of Agriculture, Kyushu University

8 Technical Official, School of Agriculture, Kyushu University

* Corresponding author (E-mail: mshimojo@agr.kyushu-u.ac.jp) analyses of forages in order to modify traditional analytic equations.

\section{APPLYING GROWTH FORCE AND LEAF-LIGHT COMPLEX TO PRODUCTION AND DIGESTION ANALYSES OF FORAGES}

\section{Modifying basic growth analysis of forages}

(A) Traditional equation

As shown by some reports (Watson, 1952; Radford, 1967; Hunt, 1990), absolute growth rate (AGR) of forages described using leaf area index (LAI) and net assimilation rate (NAR) is given by

$$
\frac{d W}{d t}=\left(\frac{1}{A} \square \frac{d W}{d t}\right) \square A,
$$

where $W=$ forage weight, $t=$ time, $A=\mathrm{LAI}, d W / d t=$ AGR, $(1 / A) \square(d W / d t)=$ NAR.

(B) Newly suggested equation

(B-1) Concept of growth force

Shimojo et al. (2006) obtained a concept of growth force by a series of calculations $(2) \sim(8)$.

$W=W_{0} \square \exp (\mathrm{RGR} \square t)$,

where RGR = relative growth rate, $W_{0}=$ the weight at $t=$ 0 .

$$
\begin{aligned}
& \mathrm{AGR}=\frac{d W}{d t}=W_{\mathbf{0}} \square \mathrm{RGR} \square \exp (\mathrm{RGR} \square t) . \\
& \mathrm{GA}=\frac{d^{2} W}{d t^{2}}=\frac{d(\mathrm{AGR})}{d t}=W_{\mathbf{0}} \square(\mathrm{RGR})^{2} \square \exp (\mathrm{RGR} \square t),
\end{aligned}
$$

where GA = growth acceleration. 
Relating equations (2) (4) gives

$\frac{\mathrm{AGR}}{W}=\frac{\mathrm{GA}}{\mathrm{AGR}}=\mathrm{RGR}$

Relating the first and second terms in (5) leads to a series of calculations as follows:

$$
\begin{aligned}
& (\mathrm{AGR})^{2}=W \square \mathrm{GA} .(6) \rightarrow \mathrm{AGR}=\sqrt{W \square \mathrm{GA}} . \\
& \rightarrow \mathrm{AGR}=\sqrt{W \square \frac{d^{2} W}{d t^{2}}} .
\end{aligned}
$$

Equations (6) (8) are a newly suggested form of AGR that might look like Newton's equation of motion (Shimojo et al., 2006), namely growth force in growth mechanics compared with force in motion. Thus, there occurs the following replacement in AGR:

AGR $=\frac{d W}{d t}$ replaced by $\mathrm{AGR}=\sqrt{W \square \frac{d^{2} W}{d t^{2}}}$.

\section{(B-2) Concept of leaf-light complex}

Reports of light environment in plant canopy (Shimojo et al., 1995a, 1998e, 2004) suggested that mean leaf area weighted with relative light intensity (MLA) gave a kind of leaf-light complex because of including both LAI and $K$ (light extinction coefficient of plant canopy) as follows:

$$
\begin{aligned}
\text { MLA } & =\left\{\int_{0}^{A} F \square 100 \square \exp \left(-K \square F^{\prime}\right) d F\right\} /\left\{\int_{0}^{A} 100 \square \exp \left(-K \square F^{\prime}\right) d F\right\} \\
& =\frac{1}{K} \square\left\{1-\frac{K \square A}{\exp (K \square A)-1}\right\},
\end{aligned}
$$

where $F$ = cumulative leaf area index from the top layer to the $j$ th layer of canopy leaves, $A=\mathrm{LAI}$ of the canopy, $K=$ light extinction coefficient of the canopy.

Equation (10) shows that MLA is affected by not only $A$ but also $K$. This viewpoint suggests that leaf-light complex is preferable for the description of light receiving performance of canopy leaves compared with the traditional treatment of leaf and light.

Thus, there occurs the following replacement in LAI:

$\mathrm{LAI}=A$ replaced by $\mathrm{MLA}=\frac{1}{K} \square\left\{1-\frac{K \square A}{\exp (K \square A)-1}\right\}$

(B-3) Combining growth forth and MLA

Combining equations (9) and (11) gives the following replacement:

$\frac{d W}{d t}=\left(\frac{1}{A} \square \frac{d W}{d t}\right) \square A$,

replaced by $\sqrt{W \square \frac{d^{2} W}{d t^{2}}}$

$$
\begin{aligned}
= & \left\{\frac{1}{\frac{1}{K} \square\left(1-\frac{K \square A}{\exp (K \square A)-1}\right)} \square \sqrt{W \square \frac{d^{2} W}{d t^{2}}}\right\} \\
& \square\left\{\frac{1}{K} \square\left(1-\frac{K \square A}{\exp (K \square A)-1}\right)\right\} .
\end{aligned}
$$

There are more pieces of information on forage growth analysis in new equation (12) than in traditional equation (1). Equation (12) shows a close relationship between growth force of forages and leaf-light complex, a new viewpoint that modifies basic growth analysis to give a deeper interpretation to growth process of forages. This is why we have made the present attempt.

\section{Modifying digestion analysis of forages}

(A) Former equation

A series of studies by Shimojo et al. (1995b, 1997, 1998a, 1998b, 1998c, 1998d, 1998f, 1998g, 1998h, 1999a, 1999 b, 1999c) reported digestion analysis of forages with growth of them. In those reports indigestion analysis was taken up frequently, because this is easier to treat than digestion analysis due to a continuous formation of indigestible materials with growth of forages. The increase in indigestibility is described as follows:

$\frac{I_{2}}{W_{2}}-\frac{I_{1}}{W_{1}}=\left(1-\frac{W_{1}}{W_{2}}\right) \square\left(\frac{\overline{\mathrm{FRI}}}{\overline{\mathrm{RGR}}}-\frac{I_{1}}{W_{1}}\right)$,

where $W=$ forage dry weight, $\mathrm{RGR}=$ forage relative growth rate, $I=$ dry weight of indigestible materials, $\mathrm{FRI}=$ formation rate of indigestible materials .

In equation (13), $\overline{\mathrm{RGR}}$ and $\overline{\mathrm{FRI}}$ show mean RGR and mean FRI over the interval $t_{1}$ to $t_{2}$, respectively. The instantaneous expression of them is given by

$\mathrm{RGR}=\frac{1}{W} \square \frac{d W}{d t}, \quad(14) \quad \mathrm{FRI}=\frac{1}{W} \square \frac{d I}{d t}$,

\section{(B) Newly suggested equation}

Equations (14) and (15) are modified under the concept of growth mechanics. Thus,

modified RGR $=\frac{1}{W} \sqrt{W \square \frac{d^{2} W}{d t^{2}}}\left(=\sqrt{\frac{1}{W} \square \frac{d^{2} W}{d t^{2}}}\right)$

modified FRI $=\frac{1}{W} \sqrt[\square]{I \square \frac{d^{2} I}{d t^{2}}}\left(=\frac{I}{W} \sqrt{\frac{1}{I} \square \frac{d^{2} I}{d t^{2}}}\right)$,

Equation (17) is derived from a series of calculations as shown below.

$\frac{1}{I} \square \frac{d I}{d t}=\mathrm{RGR}_{\mathbf{I}}, \quad(18) \rightarrow I=I_{0} \square \exp \left(\mathrm{RGR}_{\mathbf{I}} \square t\right)$

$\rightarrow \quad \frac{d I}{d t}=I_{0} \square \mathrm{RGR}_{\mathbf{I}} \square \exp \left(\mathrm{RGR}_{\mathbf{I}} \square t\right)$,

$\rightarrow \quad \frac{d^{2} I}{d t^{2}}=I_{0} \square\left(\mathrm{RGR}_{\mathrm{I}}\right)^{2} \square \exp \left(\mathrm{RGR}_{\mathrm{I}} \square t\right)$

$\rightarrow \quad \frac{d I}{d t}\left|I=\frac{d^{2} I}{d t^{2}}\right| \frac{d I}{d t}=\mathrm{RGR}_{\mathbf{I}}$

$\rightarrow\left(\frac{d I}{d t}\right)^{2}=I \square \frac{d^{2} I}{d t^{2}}$,

$\rightarrow \quad \frac{d I}{d t}=\sqrt{I \square \frac{d^{2} I}{d t^{2}}}\left(=I \square \sqrt{\frac{1}{I} \square \frac{d^{2} I}{d t^{2}}}\right)$.

where $I=$ dry weight of indigestible materials, $I_{0}=$ dry 
weight of indigestible materials at $t=0, \mathrm{RGR}_{\mathrm{I}}=\mathrm{RGR}$ of $I$, $d I / d t=$ growth rate of $I(\mathrm{GRI}), d^{2} I / d t^{2}=$ growth acceleration of $I$ (GAI), $I \square\left(d^{2} I / d t^{2}\right)=$ growth force of $I$, (1/I) $\square$ $\left(d^{2} I / d t^{2}\right)=$ GAI per unit of $I$.

Thus, equation (24) gives

modified FRI =

$$
\frac{1}{W} \square \frac{d I}{d t}=\frac{1}{W} \square \sqrt{I \square \frac{d^{2} I}{d t^{2}}}\left(=\frac{I}{W} \sqrt{\frac{1}{I} \square \frac{d^{2} I}{d t^{2}}}\right) .
$$

Therefore, there occurs the following replacement in both RGR and FRI:

$$
\begin{aligned}
& \mathrm{RGR}=\frac{1}{W} \square \frac{d W}{d t},(14) \quad \text { replaced by } \\
& \text { modified RGR }=\frac{1}{W} \square \sqrt{W \square \frac{d^{2} W}{d t^{2}}}\left(=\sqrt{\frac{1}{W} \square \frac{d^{2} W}{d t^{2}}}\right),
\end{aligned}
$$

$$
\mathrm{FRI}=\frac{1}{W} \square \frac{d I}{d t},(15) \quad \text { replaced by }
$$

$$
\text { modified FRI }=\frac{1}{W} \sqrt[\square]{I \square \frac{d^{2} I}{d t^{2}}}\left(=\frac{I}{W} \sqrt{\frac{1}{I} \square \frac{d^{2} I}{d t^{2}}}\right) .
$$

These result in the following replacement:

$$
\frac{I_{2}}{W_{2}}-\frac{I_{1}}{W_{1}}=\left(1-\frac{W_{1}}{W_{2}}\right) \square\left(\frac{\overline{\mathrm{FRI}}}{\overline{\mathrm{RGR}}}-\frac{I_{1}}{W_{1}}\right),
$$

replaced by $\frac{I_{2}}{W_{2}}-\frac{I_{1}}{W_{1}}=\left(1-\frac{W_{1}}{W_{2}}\right) \square\left(\frac{\text { modified } \overline{\text { FRI }}}{\text { modified } \overline{\mathrm{RGR}}}-\frac{I_{1}}{W_{1}}\right)$.

Modified RGR [equation (16)] shows that there are two descriptions for RGR: (1) growth force per unit of $W$, (2) growth acceleration per unit of $W$. These two kinds of expressions suggest a deeper interpretation of RGR, an improvement that is given by introducing the growth force of weight.

Modified FRI [equation (17)] shows that there are two descriptions for FRI: (1) growth force of $I$ per unit of $W$, (2) the product of $I / W$ and growth acceleration of $I$ per unit of $I$. These two kinds of expressions suggest a deeper interpretation of FRI, an improvement that is given by introducing the growth force of indigestible materials.

Therefore, there are more pieces of information on digestion analysis of forages in new equation (25) than in former equation (13). This is why we have made the present attempt.

\section{Conclusions}

The present study suggested that the application of growth forth and leaf-light complex to basic growth analysis gave new equations analyzaing production and digestion characteristics of forages more deeply compared with traditional equations.

\section{REFERENCES}

Hunt, R. 1990 Basic Growth Analysis. Unwin Hyman Ltd., London.

Kawabe, T. 2006 Standard Mechanics. Shokabo Publishing Co., Ltd., Tokyo. (written in Japanese)

Monsi, M. und T. Saeki 1953 Über den Lichtfaktor in den Pflanzengesellshaften und seine Bedeutung für die Stoffproduktion. Jpn. J. Bot., 14: 22-52

Monteith, J. L. 1965 Light distribution and photosynthesis in field crops. Ann. Bot., 29: 17-37

Radford, P. J. 1967 Growth analysis formulae-their use and abuse. Crop Sci., 7: 171-175

Shimojo, M., Y. Masuda, Y. Imura, M. Tobisa, Y. Nakano and I. Goto 1995a Estimation of light intercepting performance of plant canopy using mean leaf area weighted with relative light intensity. J. Fac. Agr., Kyushu Univ., 39: 235-242

Shimojo, M., Y. Masuda, T. Bungo, T. Kawamura and I. Goto 1995b Analytical expression for formation of indigestible materials and increase in dry matter indigestibility with growth of some tropical grasses. J. Fac. Agr., Kyushu Univ., 40: $179-188$

Shimojo, M., Y. Imura, M. Tobisa, N. Koga, T. Bungo, Y. Nakano, T. Nishihira, I. Goto and Y. Masuda 1997 Formation of indigestible materials and increase in dry matter indigestibility in the growth of two tropical forages. J. Fac. Agr., Kyushu Univ., 42: 95-99

Shimojo, M., Y. Imura, T. Bungo, M. Tobisa, N. Koga, S. Tao, M. Yunus, Z.Yin, Y. Nakano, I. Goto and Y. Masuda 1998a Formation of indigestible materials from digestible materials and photosynthates in the growth of Rodes grass (Chloris gayana Kunth). J. Fac. Agr., Kyushu Univ., 42: 355-360

Shimojo, M., T. Bungo, Y. Imura, M. Tobisa, N. Koga, S. Tao, M. Yunus, Z. Yin, Y. Nakano, I. Goto and Y. Masuda 1998b Relationship between two different-type equations analyzing increase in dry matter indigestibility with growth of forages. J. Fac. Agr., Kyushu Univ., 42: 361-364

Shimojo, M., T. Bungo, M. Tobisa, Y. Imura, N. Koga, S. Tao, M. Yunus, Z. Yin, Y. Nakano, I. Goto and Y. Masuda 1998c Accumulation of digestible materials and decrease in dry matter digestibility in the growth of two tropical grasses. $J$. Fac. Agr., Kyushu Univ., 42: 365-372

Shimojo, M., T. Bungo, Y. Imura, M. Tobisa, N. Koga, S. Tao, M. Yunus, Z. Yin, Y. Nakano, I. Goto and Y. Masuda 1998d Two different-type equations analyzing decrease in dry matter digestibility with growth of forages. J. Fac. Agr., Kyushu Univ., 42: 373-376

Shimojo, M., T. Bungo, Y. Imura, M. Tobisa, N. Koga, S. Tao, M. Yunus, Y. Nakano, I. Goto, M. Furuse and Y. Masuda 1998e Mean leaf area of the canopy for light interception by forages and mean retention time of feed in the rumen for feed ingestion by ruminants as investigated using simple models. J. Fac. Agr., Kyushu Univ., 43: 111-118

Shimojo, M., T. Bungo, Y. Imura, M. Tobisa, N. Koga, S. Tao, M. Yunus, Y. Nakano, I. Goto, M. Furuse and Y. Masuda $1998 f$ Accumulation rate of digestible materials and formation rate of indigestible materials in the description of relative growth rate of forages. J. Fac. Agr., Kyushu Univ., 43: 119-126

Shimojo, M., T. Bungo, M. Tobisa, Y. Imura, N. Koga, S. Tao, M. Yunus, Y. Nakano, I. Goto, M. Furuse and Y. Masuda 1998g An application of growth analysis method to simple correlation analysis between dry matter indigestibility and lignin content with growth of a forage. J. Fac. Agr., Kyushu Univ., 43: $127-136$

Shimojo, M., T. Bungo, Y. Imura, M. Tobisa, N. Koga, S. Tao, M. Yunus, Y. Nakano, I. Goto, M. Furuse and Y. Masuda 1998h Use of complex number in the analysis of increase in dry matter indigestibility with growth of forages. J. Fac. Agr., Kyushu Univ., 43: 137-142

Shimojo, M., T. Bungo, Y. Imura, M. Tobisa, N. Koga, T. Shao, M. Yunus, Y. Nakano, I. Goto, M. Furuse and Y. Masuda 1999a Two different-type equations of relative growth analysis for 
both forages and ruminants and deriving of them from a hypothetic equation. J. Fac. Agr., Kyushu Univ., 43: 355-364

Shimojo, M., T. Bungo, Y. Imura, M. Tobisa, N. Koga, T. Shao, M. Yunus, Y. Nakano, I. Goto, M. Furuse and Y. Masuda 1999b Accumulation of digestible materials with growth of forages and digestion of forage dry matter by in vitro incubation with rumen fluid and pepsin. J. Fac. Agr., Kyushu Univ., 43: 373-382

Shimojo, M., T. Bungo, Y. Imura, M. Tobisa, N. Koga, T. Shao, M. Yunus, Y. Nakano, I. Goto, M. Furuse and Y. Masuda 1999c Forage growth analysis, forage digestion analysis and ruminant growth analysis as related using simple equations. $J$. Fac. Agr., Kyushu Univ., 43: 383-393
Shimojo, M., Y. Asano, K. Ikeda, R. Ishiwaka, T. Shao, H. Sato, M. Tobisa, Y. Nakano, N. Ohba, Y. Yano and Y. Masuda 2004 Basic production analysis of forages using a factor of light interception property of canopy. J. Fac. Agr., Kyushu Univ., 49: 33-38

Shimojo, M., K. Ikeda, Y. Asano, R. Ishiwaka, H. Sato, Y. Nakano, M. Tobisa, N. Ohba, M. Eguchi and Y. Masuda 2006 Introducing viewpoints of mechanics into basic growth analysis - (I) Three aspects of growth mechanics compared with three laws of motion -. J. Fac. Agr., Kyushu Univ., 51: 285-287

Watson, D. J. 1952 The physiological basis of variation in yield. Adv. Agron., 4: 101-145 